\title{
Random Vibration Fatigue Analysis of Car Roof Luggage Carrier
}

\author{
Ekrem Gulsevincler ${ }^{1 *}$ \\ $\mathbf{1}^{*}$ Kastamonu University, Abana Sabahat Mesut Yilmaz Vocational School, Departmant of Electric and Energy, Kastamonu, Turkey, (ORCID: 0000-0002-4787-6275), \\ egulsevincler@kastamonu.edu.tr
}

(First received 7 April 2021 and in final form 6 December 2021)

(DOI: $10.31590 /$ ejosat.911120)

ATIF/REFERENCE: Gulsevincler, E. (2021). Random Vibration Fatigue Analysis of Car Roof Luggage Carrier. European Journal of Science and Technology, (31), 92-103.

\begin{abstract}
In this paper, random vibration analysis was applied to predict the car roof luggage carrier's fatigue life. Ansys Workbench 19.2 program was used in this study for finite element analysis. The car roof luggage carrier geometry has meshed with 325,536 nodes and 105,682 elements. Random vibration measurements were handled under two different scenarios (vehicle type and road type) and a total of four different driving speeds from previous studies. Random vibration analysis was applied by defining a $75 \mathrm{~kg}$ load on the car roof luggage carrier applied according to the vibration and PSD data obtained according to the engine, wind, and road conditions of the vehicle, and it was estimated that no fatigue damage would occur for a minimum of 103653 hours using the Steinberg method.
\end{abstract}

Keywords: Random vibration, Fatigue life, Steinberg method, PSD.

\section{Araç Tavan Bagaj Taşıyıcısının Rastgele Titreşim Yorulma Analizi}

\section{$\ddot{O} \mathbf{z}$}

$\mathrm{Bu}$ çalışmada, arabanın tavan bagaj taşıyıcısının yorulma ömrünü tahmin etmek için rastgele titreşim analizi uygulanmıştır. Bu çalışmada sonlu eleman analizi için Ansys Workbench 19.2 programı kullanılmıştır. Araba tavan bagaj taşıyıcı geometrisi, 325,536 düğüm ve 105,682 eleman ile çözüm ağı ördürülmüştür. Rastgele titreşim ölçümleri, önceki çalışmalardan iki farklı senaryo (araç tipi ve yol tipi) ve toplam dört farklı sürüş hızı altında ele alınmıştır. Aracın motor, rüzgar ve yol koşullarına göre elde edilen titreşim ve PSD verilerine göre uygulanan araç tavan bagaj taşı1cısına $75 \mathrm{~kg}$ yük tanımlanarak rastgele titreşim analizi uygulanmış ve Steinberg yöntemini kullanarak minimum 103653 saat süresince herhangi bir yorulma hasarı oluşmayacağ tahmin edilmiştir.

Anahtar Kelimeler: Rastgele titreşim, Yorulma ömrü, Steinberg yöntemi, PSD

\footnotetext{
* Corresponding Author: egulsevincler@kastamonu.edu.tr
} 


\section{Introduction}

Under the scope of structural design, mechanical parts frequently attend in vibration situations while working (Y. Li et al., 2017; Z. Luo et al., 2020). A random vibration study aims to estimate the response of the models to unexpected vibration loads. Randomness is characteristic of excitation or input. Typical applications include loads experienced by an aircraft in flight or delivery trucks running on a rough road and wave loads on an offshore structure. The vibration generated in vehicles due to motor vibration and harsh road conditions randomly occurs of many different frequencies in nature. In random vibration analysis, excitations such as displacement velocity or acceleration are not deterministic such input excitations are statistical. A statistical or probabilistic approach to determining the system's response gives us a better method for evaluating our engineering parts under random excitations.

Random vibration analysis uses a mode superposition method that requires modal analysis and PSD (power spectral density) curves. The PSD attends to these widespread designations for stationary Gaussian data. Notwithstanding, most practice appearances, for example, determining scope data representing car vibration, ordinarily, vary remarkably from this theory. The aforementioned is owing to varying situations, which appear in distinct vibration with changing excitement (Rouillard, 2007; Troncossi \& Pesaresi, 2019). Additionally, it is an inadequate depiction of non-stationary data (Trapp \& Wolfsteiner, 2021).

Considering the PSD is not an adequate characterize for such loading, its obligation to be complete by random variables that specified variations from the Gaussian hypothesis (Trapp et al., 2019). In the novel investigation, higher-order analytical consequences, e.g., skewness and kurtosis, applied to define how the probability density function (PDF) of practical loading varies from vibration loading (Kihm et al., 2013). Those onedimensional tests can be highly effective identifiers. Still, their application needs some information about the characteristics of a load (Česnik et al., 2018). Skewness is utilized to assess the symmetrical degree of a random process (H. Zhou et al., 2018).

Suppose the amplitude is constantly changing. In that case, it is helpful to observe that the excitation amplitude does not constantly change at an assigned frequency. Its avg value conduces to remain constant such load histories can be characterized statistically in terms of a power spectrum density plot. PSD spectra plots are generally supplied to the analyst. Many random processes follow a gaussian distribution, also referred to as normal distribution. The excitation is assumed to follow a Gaussian distribution. The one sigma value represents a current $68.3 \%$ of the time. In contrast, three-sigma values represent occurrence $99.7 \%$ of the time in a random vibration analysis due to the input excitations are statistical. Therefore, the spectral intensity response is usually named response PSD or RPSD (Poshtan et al., 2018). Response PSD is like an input PSD, but it represents the output measured at a given location.

Since higher-order consequences are sensible to various outcomes that substantially decrease the stationary Gaussian basis, those may be powerful review parts, nonlinearities, or non-stationary responses. Accordingly, the variety of typical vibration loading through consequences might be vague. So cases were presented in Trapp \& Wolfsteiner, (2019) those loads of the equivalent PSD and kurtosis value could precisely differ in their fatigue capability. Kurtosis can not just be applied to specify a Gaussian and non-Gaussian pattern but notably distinguishes super-Gaussian and sub-Gaussian. The superGaussian pattern holds a narrow amplitude pattern centre region with a greatly more extended tailpiece (H. Zhou et al., 2018).

Rahim et al., (2021) researched the fatigue life forecast of a car suspension system exposed to random vibrations. Typically, the fatigue data improvement method is applied to treat the original stochastic vibration data. Nevertheless, this procedure appears incorrect through its time and repetition characteristics. (Wen et al., 2020). Besides, the improvement vibration data do not afford the repetition information beneficial in ascertaining vibration data precision. (Putra et al., 2020).

Most studies applied in vibration situations are constrained to random vibration filling, preferably of typical harmonious excitations. Notwithstanding, a massive division of high-cycle fatigue examination is unaccompanied touched by foretelling electronic components' fatigue life presented to a random vibration (Al-Yafawi et al., 2010). Chen et al., (2008) mixed the vibration breakdown review, FEA, and analytical formularization to determine the electronic parts' fatigue life. Che \& Pang, (2009) used fatigue inspection and examination arrangement for solder joint fatigue life estimate. Perkins \& Sitaraman, (2004) adopted a experiment to distinguish the fatigue breakdown for ceramic support framework arrangement. Yang et al., (2000) described the changing characteristics of a plastic globe framework array modelling.

In the field of fatigue analysis due to random vibration, Gharaibeh \& Pitarresi, (2019); Pitarresi, (1990) and Pitarresi et al., (1991) examined the modelling methods of electronic parts that dominated vibration loading. They looked at lead/solder response and estimated its fatigue life (Yu et al., 2011). Wong et al., (2000) revealed an empirically verified vibration fatigue breakage model. Beneficial strains were computed and consolidated with the $3 \sigma$ procedures to estimate solder joint survivability. Li, (1999) exhibited a breakdown analysis classification of parts under the auto vibration conditions.

In fatigue life examination that suggested fracture beginning, fracture distribution and stress interpretation, the loading records encountered by the parts were applied to describe the responses that happened with the worked bodies (Kim et al., 2019; Leitner \& Figuli, 2018; Rahim et al., 2021; Yuan et al., 2019). Loading records can be taken from data or trial load estimations (Chipman \& Avitabile, 2012; Kong et al., 2018; Putra et al., 2015). Durableness examination of a random vibration encountered by a part can be protracted and merge low and high amplitude periods (Zhang et al., 2018). Consequently, designers propose to reduce low amplitude periods and stimulate fatigue examination.

The fatigue life investigation of a vehicle coil spring system is vital in revealing a car since it is everlastingly and straight proved to change loads while traveling. In addition, the coil spring further restricts the car from transporting damage and consume when traveling above hits and drops and still even drive covers (Jiregna \& Sirata, 2020). The variety of driveway characterizations might induce fatigue breakdown in the coil spring operation owing to the system's repetition strain and force. Fatigue breakdown may promote the latest failure of suspension parts under particular situations (Zakaria et al., 
2018). In the fatigue life forecast of a vehicle coil spring system, behaviour propositions are ordinarily applied. The structural parts' varying stress responses are induced in the vibration conditions, leading to vibration fatigue breakdown. Seldom geometric disruptions, e.g., notches, endure in the structural features owing to the specific requirements. Below the random fatigue loadings, a notch can generate the stress distribution influence and loading disproportionately distribution influence in the notch circumference (P. Luo et al., 2019). Vibration fatigue life forecasted of the uniform parts (Aykan \& Çelik, 2009; Mršnik et al., 2013, 2016) and notched parts (Gao et al., 2019; Ge et al., 2015; He et al., 2015; Z. Luo et al., 2019; Yadong Zhou \& Tao, 2019) ought fascinated involved in recent years (Z. Luo et al., 2020).

S-N and E-N curves are commonly used in fatigue life estimates of bodies. Zhou et al., (2010) has suggested the S-N representations for SAC305 and Sn37Pb. Chin et al., (2008) wrote a fatigue depiction with the E-N curve for the BGA part. Still, the fatigue endurance for SAC compounds with separate Ag contentment was studied entirely for them originally. Besides, an estimation method bottomed on experimental vibration analyses and FEA to predict the fatigue life of parts.

The RPSD was taken and applied in determining the acquired damage which is further sensible than the generally used $3 \sigma$ scheme (Steinberg, 1988). García et al., (2018) used Steinberg's methodology to estimate the fatigue life of materials utilised in the space application applying FEA. Yet, since the $3 \sigma$ stresses are statistical models, the $3 \sigma$ process presents responsive limited reliable fatigue life prediction, as explained in the earlier (Al-Yafawi et al., 2010), than the method utilised in this area.

\section{Material and Method}

\subsection{Experimental Set-up and Test Car}

To perform the vehicle roof luggage carrier's random vibration fatigue analysis, it is needful to measure the vibration on a sample passenger vehicle where the roof luggage will be mounted. Random vibration measurements were handled under two different scenarios (vehicle type and road type) and a total of four different driving speeds from previous studies. Specifications selected for random vibration measurements are given in Table 1.

Table 1. Specification of random vibration experimental setup under two scenarios

\begin{tabular}{|l|c|c|c|c|}
\cline { 2 - 5 } \multicolumn{1}{c|}{} & \multicolumn{3}{c|}{ Scenario 1 } & Scenario 2 \\
\hline Data source & \multicolumn{2}{c|}{ (H. Zhou et al., 2018) } & (EnDAQ, 2021) \\
\hline Vehicle & \multicolumn{3}{|c|}{ Skoda Superb, 2015 } & Ford Taurus, 2003 \\
\hline $\begin{array}{l}\text { Road type and } \\
\text { route }\end{array}$ & \multicolumn{3}{|c|}{ Urban road in South China } & Highway in USA \\
\hline $\begin{array}{l}\text { Speed, km/h } \\
\text { Overall vertical } \\
\text { gRMS values, g }\end{array}$ & 0.149 & 0.166 & 0.162 & 6.06 \\
\hline $\begin{array}{l}\text { mean of moving } \\
\text { RMS in vertical } \\
\text { direction, g }\end{array}$ & 0.142 & 0.160 & 0.157 & 6.06 \\
\hline Kurtosis & 13.5 & 8.77 & 6.62 & 3.02 \\
\hline Skewness & -0.190 & -0.140 & -0.120 & -0.011 \\
\hline
\end{tabular}

In scenario one, 2015 Skoda Superb model car were taken for study. The authors used a data recorder (SAVER 3X90, Lansmont Corporation, Monterey, CA, USA), including an established-in tri-ax accelerometer, to obtain the vibration signals in vertical orientation. The sequence of any course was more than thirty min. (H. Zhou et al., 2018).
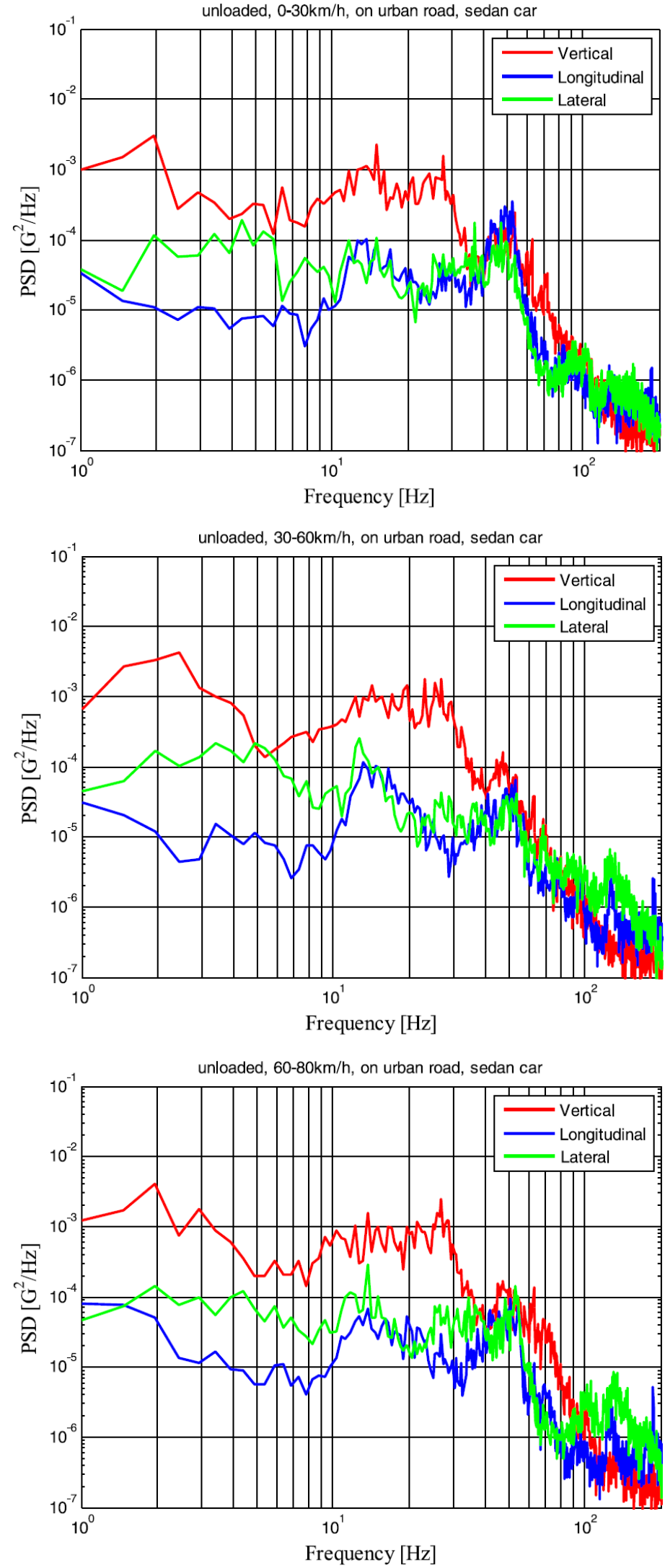

Fig. 1. PSD plots of scenario 1 (H. Zhou et al., 2018) 
Whereas in scenario two, the vibration measurement vehicle is a 2003 Ford Taurus model car $(E n D A Q, 2021)$. The author mounted an accelerometer in his auto's console. The vehicle was driven on a highway at $65 \mathrm{mph}(\sim 105 \mathrm{~km} / \mathrm{h})$. An accelerometer time history from this road test is given in Fig. 2. The PSD is shown in Fig. 3 (EnDAQ, 2021).

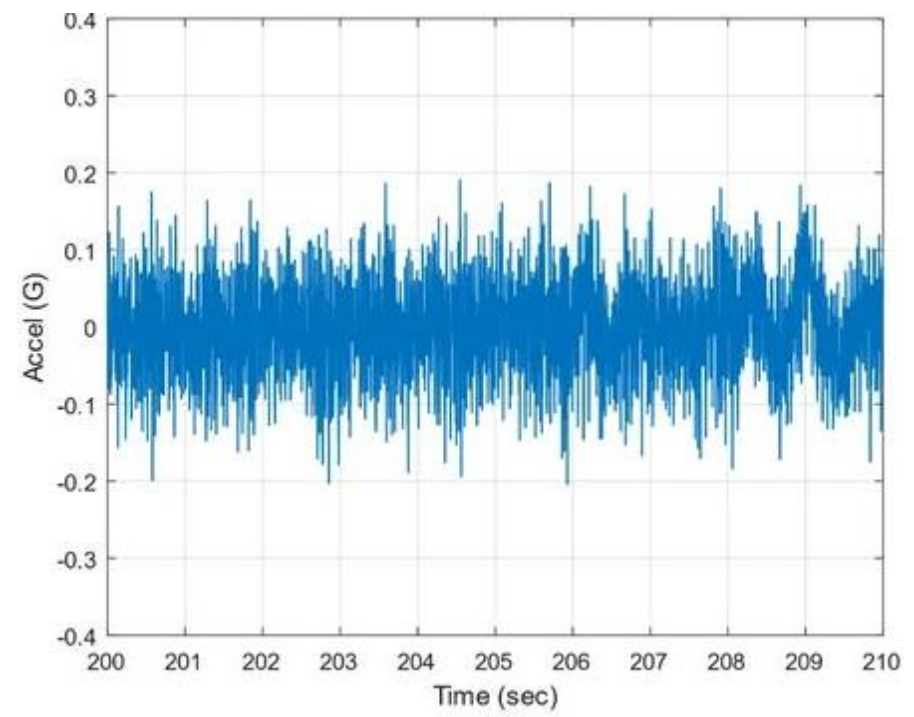

Fig. 2. Taurus time history $(E n D A Q, 2021)$

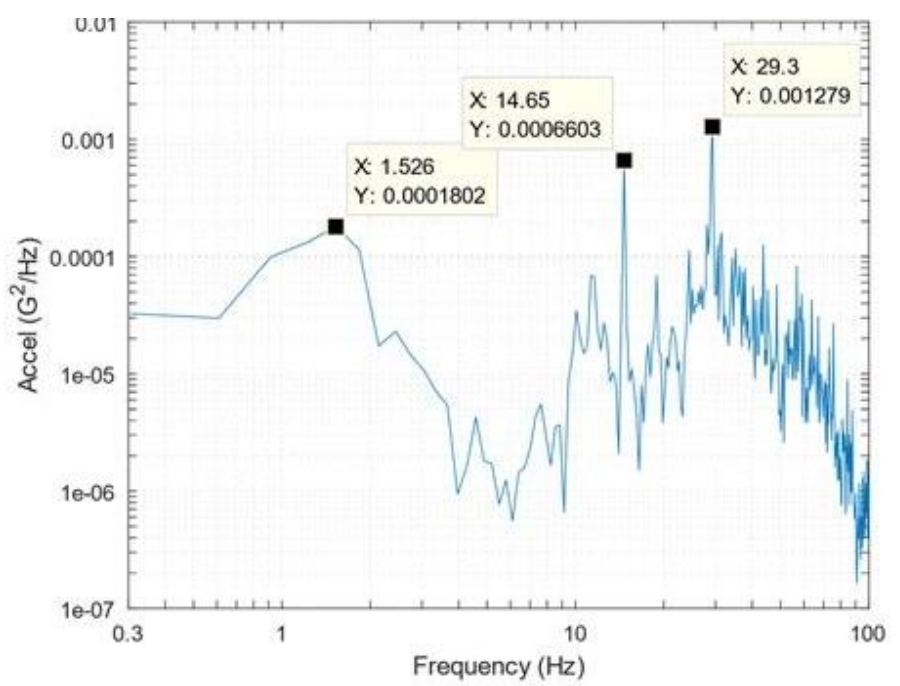

Fig. 3. Taurus PSD $(E n D A Q, 2021)$

\subsection{Car Roof Luggage Carrier Geometry}

The CAD drawing of the car roof luggage carrier, which is the subject of this paper, is given in Fig. 4, and its manufactured and assembled view is given in Fig. 5. A wall thickness of 1.5 $\mathrm{mm}$ in dimensions of $1250 \times 1000 \mathrm{~mm}$. It has seven intermediate bars and four mounting connectors. Unlike other parts, the mounting connectors of the vehicle have a wall thickness of $5 \mathrm{~mm}$.
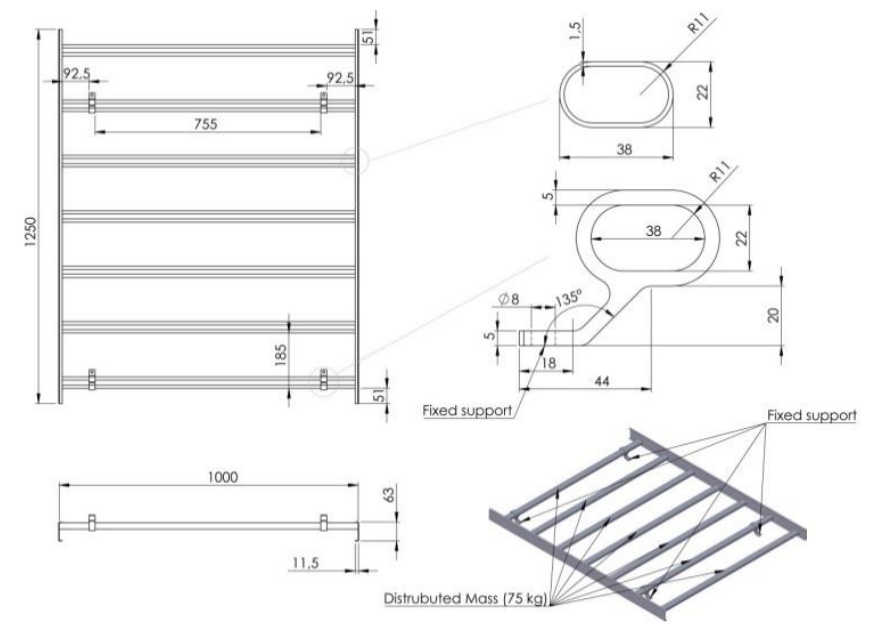

Fig. 4. 3D model of car roof luggage carrier

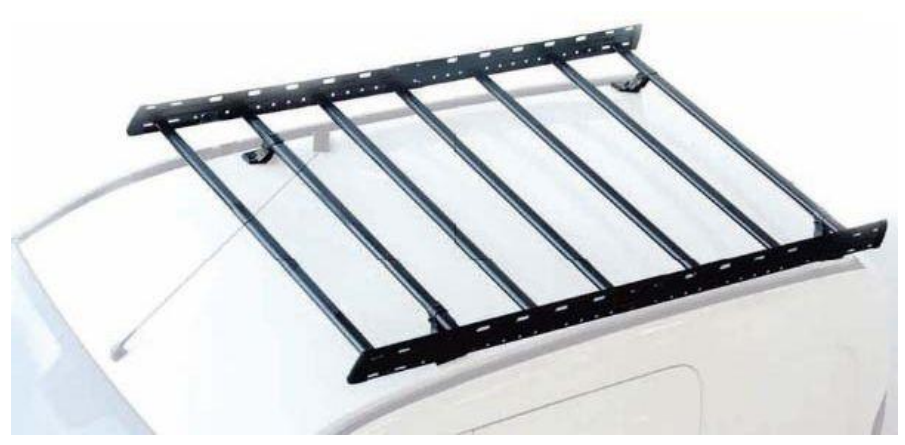

Fig. 5. Car roof luggage carrier mounted in a car

\subsection{Finite Element Analysis}

As mentioned in the introduction section, to perform random vibration analysis, it is necessary to perform modal analysis and obtain natural frequencies according to fashion shapes. Also, the modal analysis uses the static structural prestress. Ansys Workbench 19.2 program was used in this study for FEA. The interconnection of static structural, modal and random vibration analysis is given in Fig. 6.

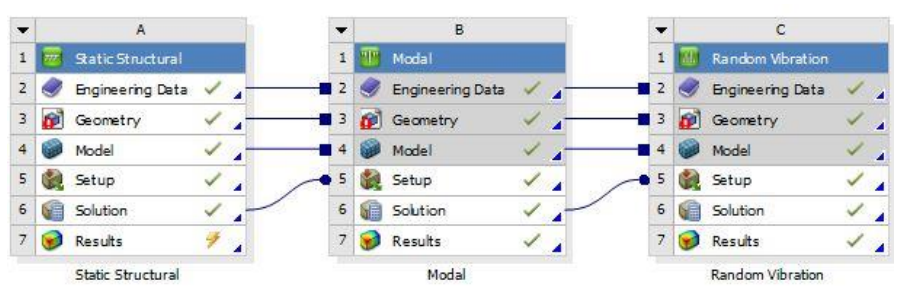

Fig. 6. Ansys Workbench project schematic

Geometry must have meshed before finite element analysis. The car roof luggage carrier geometry has meshed with 325,536 nodes and 105,682 elements. The higher the number of elements in the mesh, the more sensitive the FEA analysis result. However, a high number of elements requires high system resources. For this, an optimum mesh quality/number of elements should be preferred. In this study, knitted mesh quality was examined, and it was found that it was sufficient for this analysis. The mesh topology is shown in Fig. 7. Mesh element quality is minimum 0,32639, maximum 0,99994 and average 0,71197 (Fig. 8). 


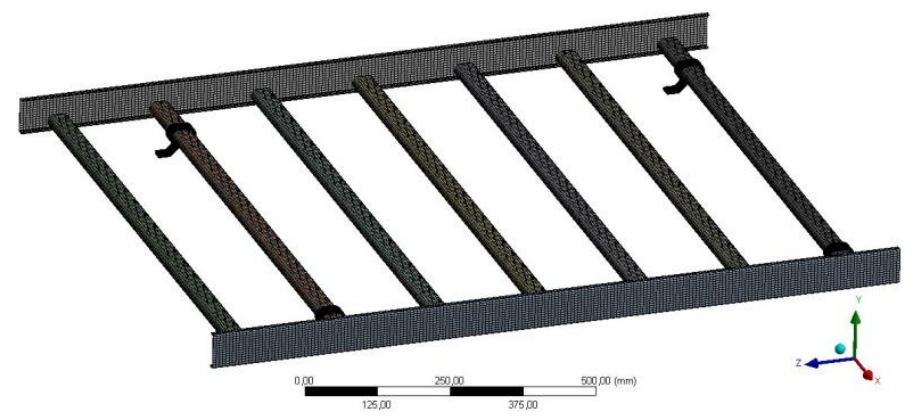

Fig. 7. Mesh topology

\subsubsection{Static Structural Analysis}

Which is the first step of the FEA analysis, the analysis was performed by applying for the fixed support, distributed mass (75kgf), and gravity in the -y-direction specified. Boundary conditions are also shown in Fig. 4.

\subsubsection{Modal Analysis}

A geometry has as many degrees of freedom as a mode shape. Typically, an object has six degrees of freedom: rotation in three directions and translation in three directions in space. This means that the mechanism will have a mode shape as much as the degree of freedom. This study is sufficient to consider the first six modes as a fixed single-assembled geometry is used instead of a mechanism.

\subsubsection{Random Vibration Analysis}

In this analysis, PSD-G acceleration data obtained from Fig. 3 is defined as input data. Random vibration analysis is solved by including the natural frequencies calculated due to the modal analysis and the PSD-G acceleration input data in the calculation. As a consequence of random vibration examination, deformation, stress, and fatigue life estimates are obtained.

\subsubsection{Fatigue Theory and Steinberg Formulation}

The goal of conducting a random vibration examination on a structure is to foretell fatigue life. The fatigue life of components while using cyclic vibration is while the damage can be determined utilizing Miner's Rule, affirming that separate events can explain the method. A spectrum of amplitudes of stress periods can be determined. Additionally, it is estimated that a constant-amplitude S-N curve is possible for a specific material (Ballesteros, 2018). This curve is agreeable with the definition of stress; that is, there is no explicit consideration of the probability of mean stress at the point mentioned above (Wirsching et al., 2006).

Fig. 9 (Wirsching et al., 2006) represents a stress spectrum defined as a progression of constant-amplitude blocks, in which each block has a stress amplitude $S_{i}$ and the total quantity of implemented cycles $n_{i} . N_{i}$ is the cycle of breakdown based on the $\mathrm{S}-\mathrm{N}$ curve.
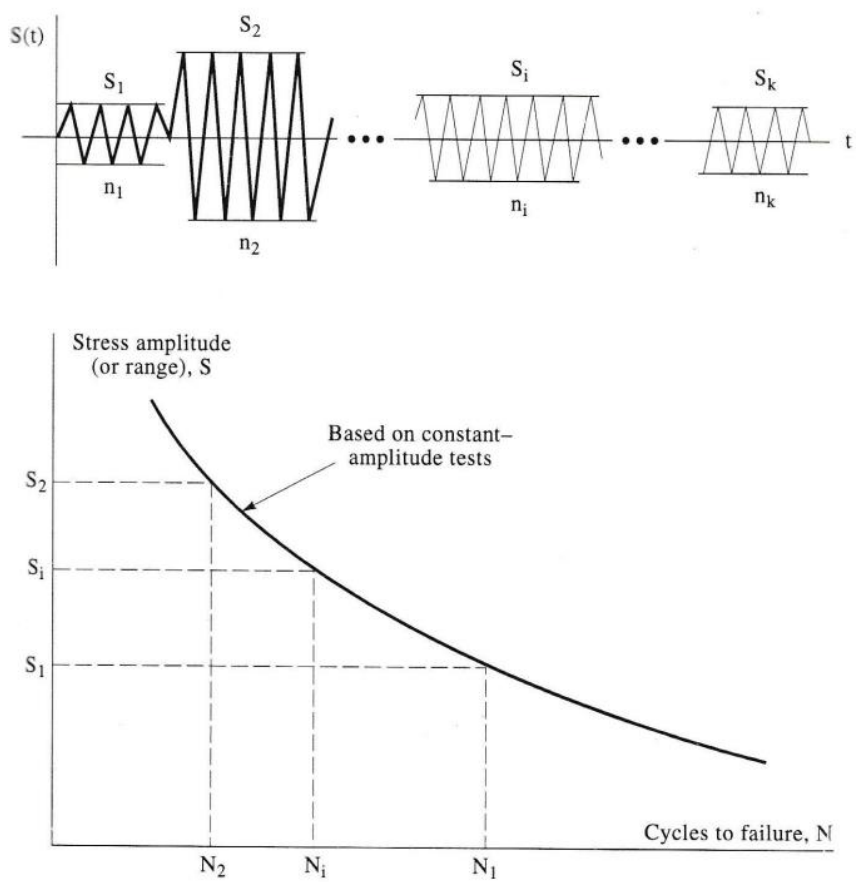

Fig. 9. Explanation of Miner's Rule (Wirsching et al., 2006)

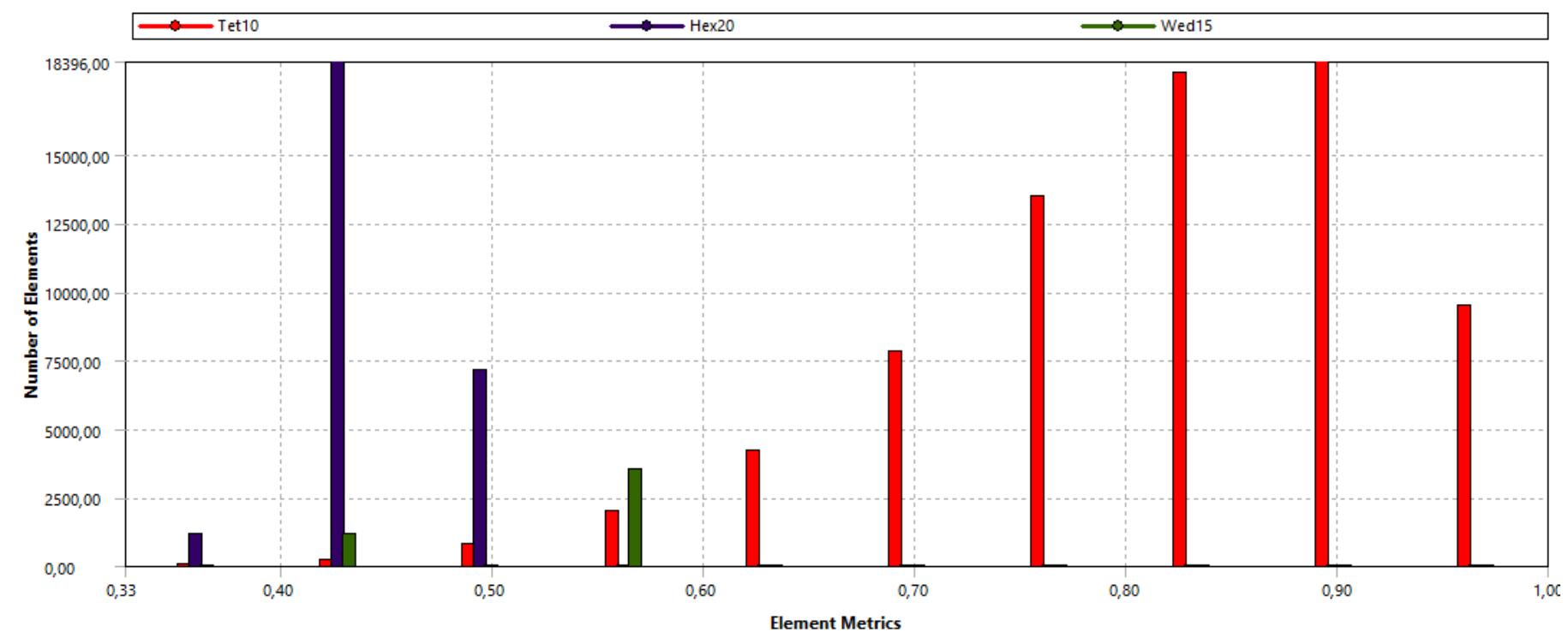

Fig. 8. Mesh element quality details 
It is seen that the first block has a stress $S_{1}$, and from the S$\mathrm{N}$ curve, the quantity of cycles to breakdown at that stress level is $N_{1}$. According to Miner's Rule, just $n_{i}<N_{i}$ cycles are concerned, allowing breakdown has not happened. Thus, the fractional damage $n_{i}=N_{i}$ is determined, which means that breakdown happens if this fraction is more notable than one. Consequently, Miner's rule declares the following (Ballesteros, 2018; Budynas et al., 2005; Wirsching et al., 2006).

The stress of the fractional damage (Wirsching et al., 2006):

$S_{i}=\frac{n_{i}}{N_{i}}$

Amount of fractional damages is the total damage (Wirsching et al., 2006):

$D=\frac{n_{1 \sigma}}{N_{1 \sigma}}+\frac{n_{2 \sigma}}{N_{2 \sigma}}+\frac{n_{3 \sigma}}{N_{3 \sigma}}$

In each of these ranges, the number of cycles $\left(N_{1 \sigma}, N_{2 \sigma}\right.$ and $N_{3 \sigma}$ ) required for damage It can be ascertained from the S-N curve of the material (Steinberg, 1976). Breakdown will ocur at (Wirsching et al., 2006):

$D \geq 1$

Miner's Rule has some constraints on the subject of results. Miner's Rule does not regard into statement the order in which the sequences were implemented. There are states where the states beginning damage to the structure may decrease the strength limit of the part. For example, suppose a situation where the last period does not generate any damage because the stress level endures in the infinite life area of the material S-N curve. As a conclusion of the damage affected owing to the previous cycles, there may be a modification in the strength limit of the materials in influence following deliberate damage. Miner's Rule does not consider this (Ballesteros, 2018).

Part fatigue failure occurs up to cumulative damage in a value. The cumulative damage breakdown is an example of the structure's breakdown forms in the random operation environment, damaging the microdamage. The fatigue failure is calculated for stochastic vibrations and continuous stress amplitude in agreement with the $\mathrm{S}-\mathrm{N}$ curve of the material under consideration. Each period will generate cumulative damage in the random vibration situation like the stochastic vibration fatigue approach (Tao et al., n.d.). In the random vibration situation, fatigue estimation is comparatively complicated since the structure's response is an arbitrary amount. In practice, the $3 \sigma$ method proposed by Steinberg is broadly used.

Steinberg, (1988) concluded that the possibility density function of spectrum range for a broadband signal tendency to a Gaussian frequency and suggested an RMS (Root Mean Square) amplitude. The Steinberg equation is given in Equation (4) (Halfpenny \& Kihm, 2010).

$\mathrm{N}(\mathrm{S})=\mathrm{E}(\mathrm{P}) \cdot \mathrm{t} \cdot \mid \begin{gathered}0.683 \times 2 \mathrm{RMS} \\ +0.271 \times 4 \mathrm{RMS} \\ +0.043 \times 6 \mathrm{RMS}\end{gathered}$

According to Equation (5), the possibility of not passing a value of acceleration corresponding to the $1 \sigma$ is $68.3 \%$. Likewise, the possibility concerning not exceeding the $2 \sigma$ and $3 \sigma$ values are $95.4 \%$ and $99.73 \%$, respectively. The stress value higher than what happens inside $0.27 \%$ of the timescale assumed that it does not generate any breakdown. (Tao et al., n.d.). Where
$\mathrm{N}$ is the assumed number of cycles of stress range $\mathrm{S}$ happening in $\mathrm{t}$ seconds and $\mathrm{E}[\mathrm{P}]$ is the assumed amount of peaks concerned by Equation (5) (Halfpenny \& Kihm, 2010).

$E(\mathrm{P})=\sqrt{\frac{\mathrm{m}_{4}}{\mathrm{~m}_{2}}}$

Where $m_{2}$ and $m_{4}$ are the fourth and second moments of section of the PSD respectively: where the $n^{\text {th }}$ moment of area is determined as (Halfpenny \& Kihm, 2010):

$m_{\mathrm{n}}=\int f^{n} \cdot S(f) d f$

Where $S(f)$ is the value of the single-sided PSD at frequency $f \mathrm{~Hz}$ (Halfpenny \& Kihm, 2010). RMS value for a continuous stationary Gaussian process $\sigma$ given in Equation (7):

$\sigma=\sqrt{\mathrm{m}_{0}}=\sqrt{\int_{0}^{\infty} \mathrm{S}(\mathrm{f}) \mathrm{df}}$

Where $\mathrm{m}_{0}$ is the $0^{\text {th }}$ moment of area of the power spectral density (area under the curve) (Halfpenny \& Kihm, 2010).

The Steinberg formulation is frequently used in the literature (An et al., 2019; Ben Fekih et al., 2015; Dehbi et al., 2005; Demirel \& Kayran, 2019; Gharaibeh, 2020; Kersch et al., 2020; L. Li et al., 2018; Park \& Oh, 2021; Schriefer \& Hofmann, 2019; Xia et al., 2019).

\subsubsection{Material and $S$ - $N$ curve}

The car roof luggage carrier is designed from St 44-2 (S235JRG2) quality structural steel material. The yield strength of the material is $250 \mathrm{MPa}$, and tensile strength is $460 \mathrm{MPa}$.

$\mathrm{S}-\mathrm{N}$ (Wohler) curve shows the magnitude of the stress amplitude corresponding to the number of cycles a material is damaged. In this curve, the stress as well as the amount of cycles are usually shown in logarithmic scales. A loading history and an S-N curve, and Miner's Rule can be used to determine the mechanical part's cumulative damage or fatigue life. The S-N curve of St 44-2 (S235JRG2) quality structural steel material used in this study is given in Fig. 10.

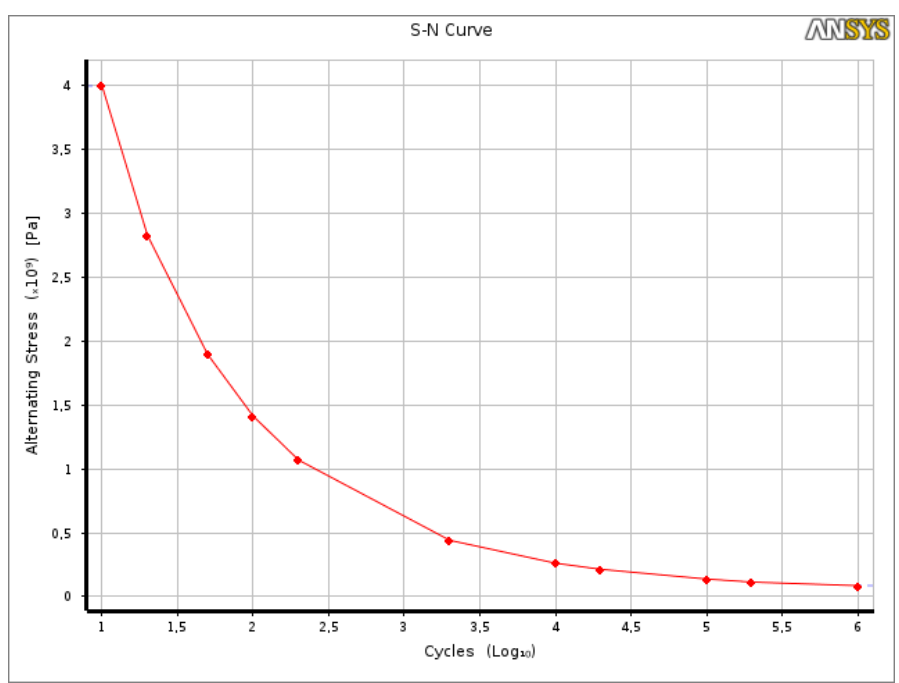

Fig. 10. St 44-2 material S-N curve 


\section{Results and Discussion}

\subsection{Static Structural Analysis Results}

As a result of the static structural analysis, the model's average stress value is $6,3607 \mathrm{MPa}$, and the average total deformation is $0,26845 \mathrm{~mm}$. Equivalent (Von-Mises) stress result is given in Fig. 11

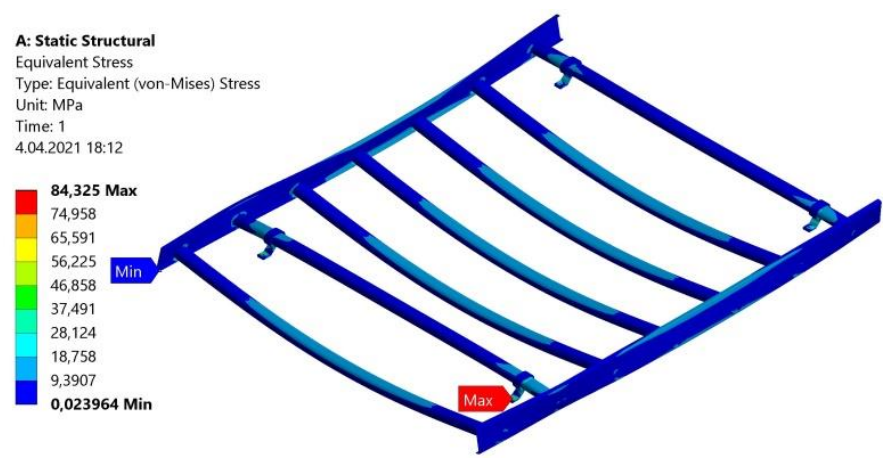

Fig. 11. Equivalent (Von-Mises) stress result

\subsection{Modal Analysis Results}

The modal analysis uses the static structural pre-stress. Once completed, a note from the modal results, the model's natural frequencies range from 48 to 70 hertz for the first six modes. Table 2 shows the first six natural frequencies and mode shapes as received from the modal analysis result.

Table 2. Natural frequencies and mode shapes

\begin{tabular}{|c|c|c|}
\hline & $\begin{array}{c}\text { Natural } \\
\text { frequency } \\
(\mathbf{H z})\end{array}$ & Mode shape \\
\hline Mode 1 & 48,745 & \\
\hline Mode 2 & 54,810 & \\
\hline Mode 3 & 62,057 & \\
\hline Mode 4 & 66,569 & \\
\hline Mode 5 & 68,799 & \\
\hline Mode 6 & 69,943 & \\
\hline
\end{tabular}

\subsection{Random Vibration Analysis Results}

PSD G acceleration scope this to all supports and set the direction to the $\mathrm{y}$-axis to see the probability of a component deforming in the vertical (y) direction. The PSD data given in Fig. 1-3 is defined as PSD $G$ acceleration input in random vibration analysis. PSD $\mathrm{G}$ acceleration tabular data is given in Table 3.

Table 3. PSD G acceleration tabular data.

\begin{tabular}{|c|c|c|c|}
\hline & $\begin{array}{l}\text { Speed } \\
(\mathbf{k m} / \mathbf{h})\end{array}$ & $\begin{array}{l}\text { Frequency } \\
(\mathbf{H z})\end{array}$ & $\begin{array}{c}\text { G acceleration } \\
\left(\mathbf{G}^{2} / \mathbf{H z}\right)\end{array}$ \\
\hline \multirow{18}{*}{ 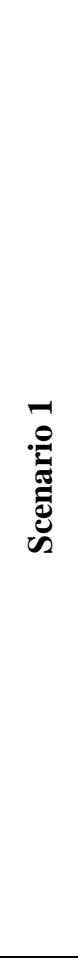 } & \multirow{6}{*}{$0-30$} & 45 & $8,00 \mathrm{E}-05$ \\
\hline & & 50 & $6,00 \mathrm{E}-05$ \\
\hline & & 55 & $1,00 \mathrm{E}-05$ \\
\hline & & 60 & $8,00 \mathrm{E}-06$ \\
\hline & & 65 & $2,00 \mathrm{E}-06$ \\
\hline & & 70 & $1,50 \mathrm{E}-06$ \\
\hline & \multirow{6}{*}{$30-60$} & 45 & $1,00 \mathrm{E}-05$ \\
\hline & & 50 & $2,00 \mathrm{E}-05$ \\
\hline & & 55 & $1,00 \mathrm{E}-05$ \\
\hline & & 60 & 2,00E-06 \\
\hline & & 65 & $1,50 \mathrm{E}-06$ \\
\hline & & 70 & $1,80 \mathrm{E}-06$ \\
\hline & \multirow{6}{*}{$60-80$} & 45 & $3,00 \mathrm{E}-05$ \\
\hline & & 50 & $2,00 \mathrm{E}-05$ \\
\hline & & 55 & $8,50 \mathrm{E}-06$ \\
\hline & & 60 & $1,25 \mathrm{E}-06$ \\
\hline & & 65 & $4,00 \mathrm{E}-06$ \\
\hline & & 70 & $1,50 \mathrm{E}-06$ \\
\hline \multirow{7}{*}{ 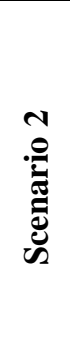 } & \multirow{7}{*}{105} & 45 & $1,40 \mathrm{E}-05$ \\
\hline & & 50 & $6,40 \mathrm{E}-06$ \\
\hline & & 55 & $1,10 \mathrm{E}-05$ \\
\hline & & 60 & $5,30 \mathrm{E}-06$ \\
\hline & & 65 & $1,05 \mathrm{E}-05$ \\
\hline & & 70 & 4,40E-06 \\
\hline & & 75 & $4,10 \mathrm{E}-06$ \\
\hline
\end{tabular}

Three sigma equivalent stress result of random vibration analysis solved with PSD G acceleration data is given in Fig. 12. According to the Steinberg's method, the three sigma stress results from the value, which includes $99.73 \%$ of all stress values due to random vibration loading. This will be the best bet at accurately showing the amount of stress that model due to random vibration. 
(a)

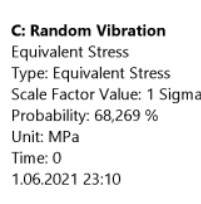

a) 1,9967 Max
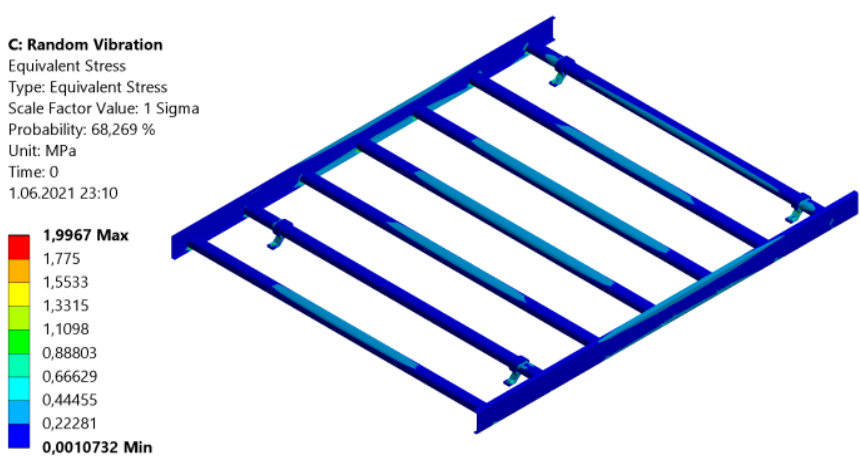

C: Random Vibration C: Random Vibration
Equivalent Stress 2
Type: Equivalent Stress Type: Equivalent Stress
Scale Factor Value: 3 Sigma Probability: $99,73 \%$ Unit: MPa
Time: 0 1.06.2021 23:08

(b)
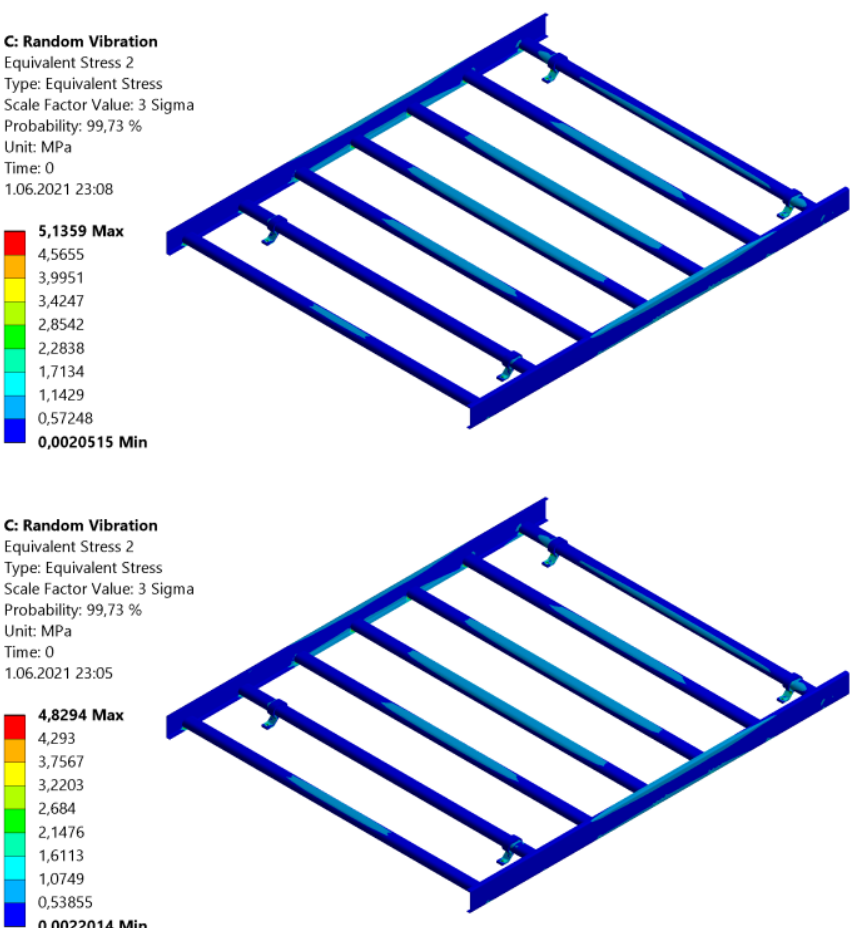

(c)
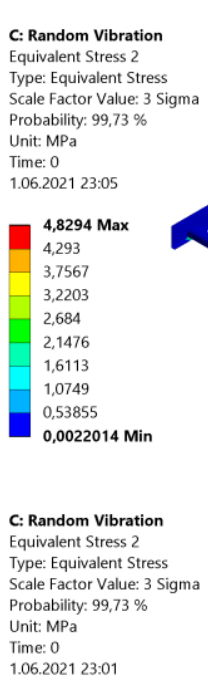

(d)
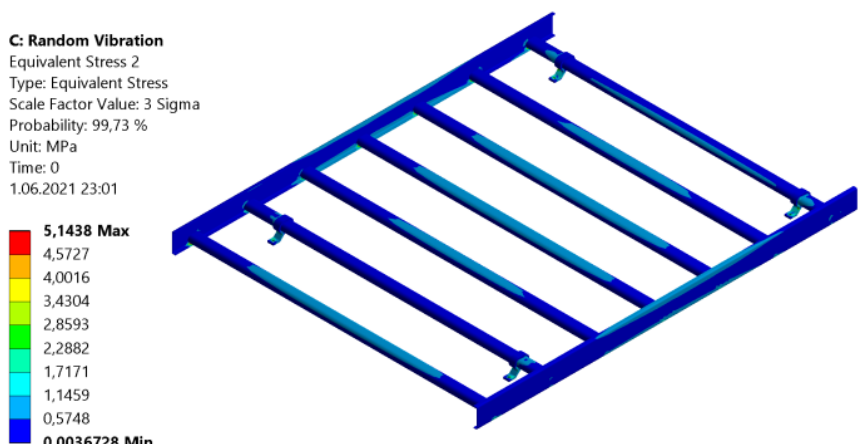

Fig. 12. Equivalent stress result $(3 \sigma)$ a) Scenario $10-30 \mathrm{~km} / \mathrm{h} \mathrm{b}$ ) Scenario $130-60 \mathrm{~km} / \mathrm{h} \mathrm{c}$ ) Scenario $160-80 \mathrm{~km} / \mathrm{h} \mathrm{d}$ ) Scenario 2 $105 \mathrm{~km} / \mathrm{h}$

According to the three-sigma directional deformation result, it can be concluded that the maximum deformation of the model is in the range of approximately $0.065-0.080$ millimeters with a $99.7 \%$ probability (Fig. 13). Notice that there is no deformation shape since these results are statistical in nature. (a)

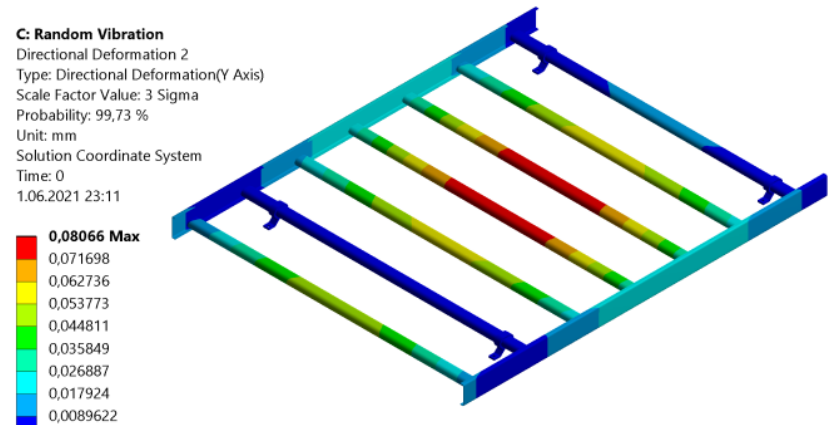

0,0089622

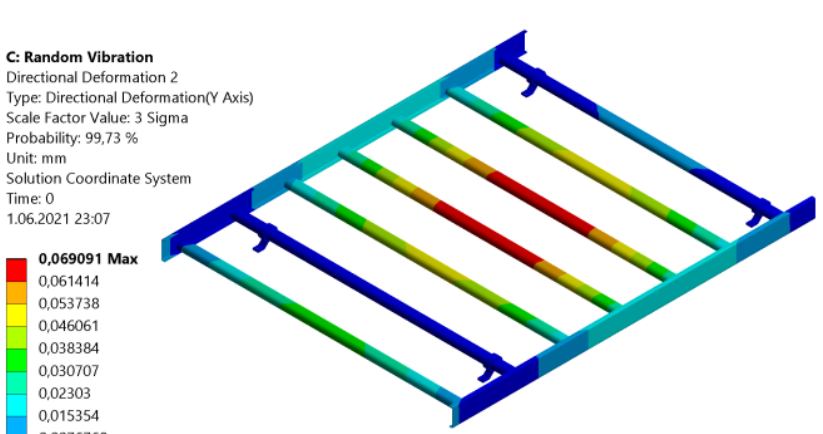

0.015354

0 Min
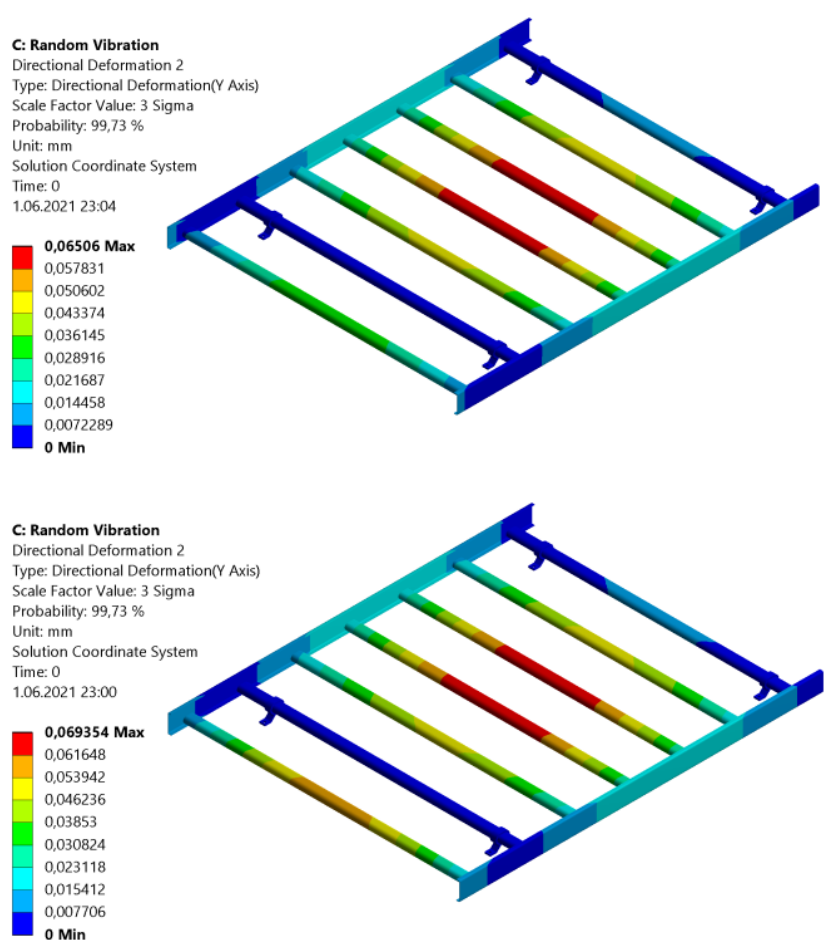

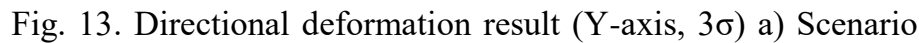
$10-30 \mathrm{~km} / \mathrm{h} \mathrm{b}$ ) Scenario $130-60 \mathrm{~km} / \mathrm{h}$ c) Scenario $160-80 \mathrm{~km} / \mathrm{h}$ d) Scenario $2105 \mathrm{~km} / \mathrm{h}$

The response PSD displacement is computed in the selected vertex (Fig. 14) of the geometry where displacement values are highest. Resonant frequencies and particular transmissibility achieved within spectrum examination additionally confirm the experimental random vibration sequences. In other words, the response PSD provides information about where the average power is distributed as a function of frequency. The summit displacement response occurs at the resonant frequencies on the assembly zone (Fig. 15). 
C: Random Vibratio Response PSD $1.06202120: 46$

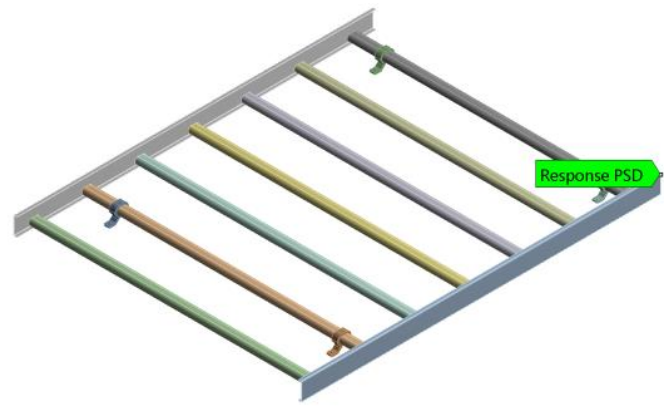

Fig. 14. Response PSD vertex selection

(a)

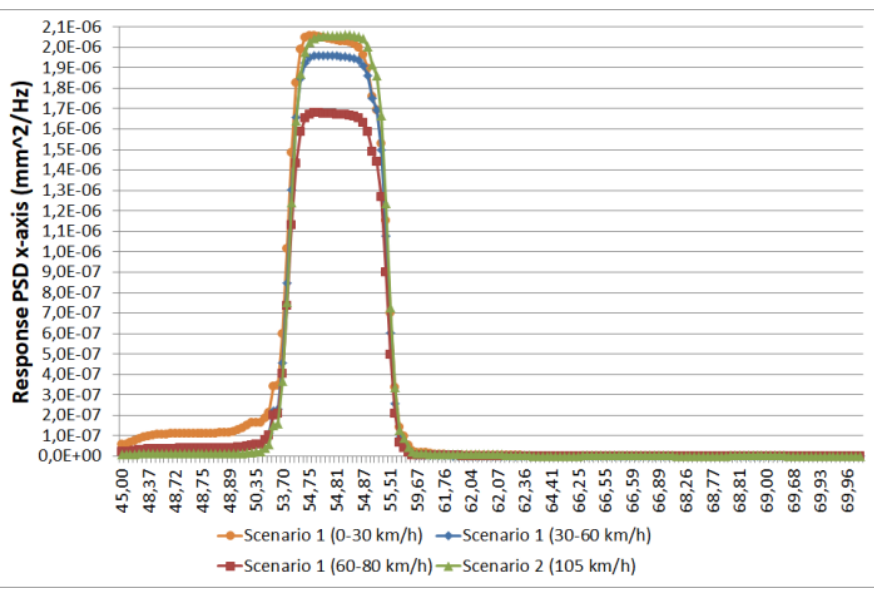

(b)

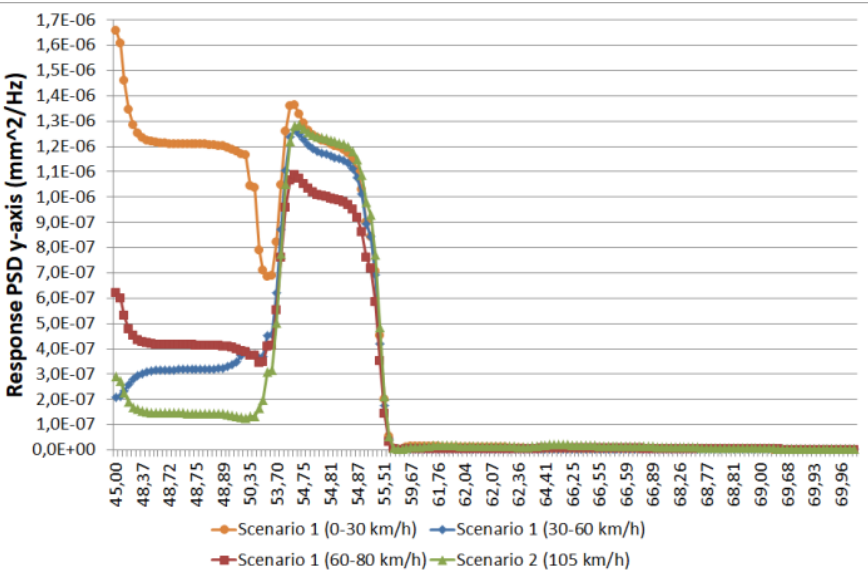

(c)

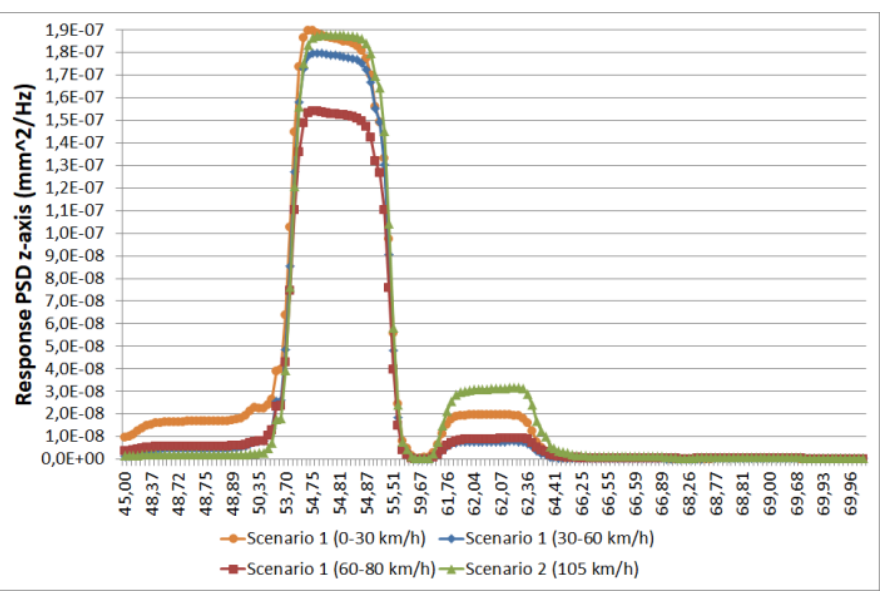

Fig. 14. Response PSD a) $\mathrm{x}$-axis b) y-axis c) z-axis

The fatigue life of the model calculated according to the Steinberg's method is shown in Fig. 15. According to this result, when the material starts to get tired, and the first fracture occurs due to fatigue, the minimum time varies between $3.73 \mathrm{E}+08$ and 7.07E +08 seconds. Considering four different random vibration analyzes, the lowest fatigue life was obtained at Scenario 1 and $0-30 \mathrm{~km} / \mathrm{h}$ driving speed, and the first fracture occurs due to fatigue was calculated as $3.73 \mathrm{E}+08$ seconds. This time is equal to 103653 hours. This means, if a car roof luggage carrier is used for eight hours a day at an average speed of $0-30 \mathrm{~km} / \mathrm{h}$ with a 75 $\mathrm{kg}$ load with a 2015 Skoda brand Superb Model vehicle, it will not suffer any fatigue damage 17275 days (approximately 47.3 years).

(a)

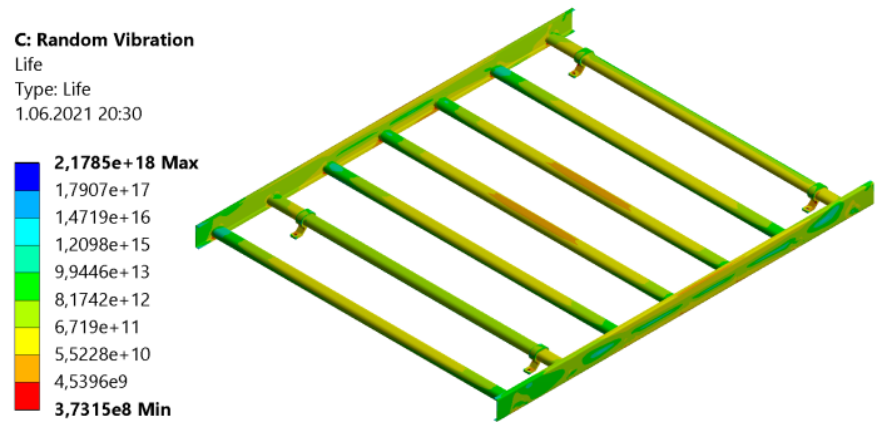

(b)

$$
\begin{aligned}
& \text { C: Random Vibration } \\
& \text { Life } \\
& \text { Type: Life } \\
& \text { 1.06.2021 20:37 }
\end{aligned}
$$

8,3727e+18 Max
$6,2304 \mathrm{e}+17$
$4,6362 \mathrm{e}+16$
$3,4499 \mathrm{e}+15$
$2,5672 \mathrm{e}+14$
$1,9103 \mathrm{e}+13$
$1,4215 \mathrm{e}+12$
$1,0578 \mathrm{e}+11$
7,8715e9
$\mathbf{5 , 8 5 7 4 e 8}$ Min

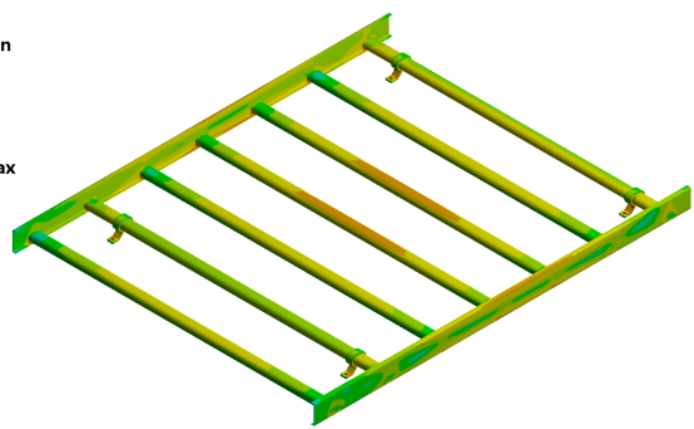

C: Random Vibration Life Type: Life 1.06.2021 20:41

(c)
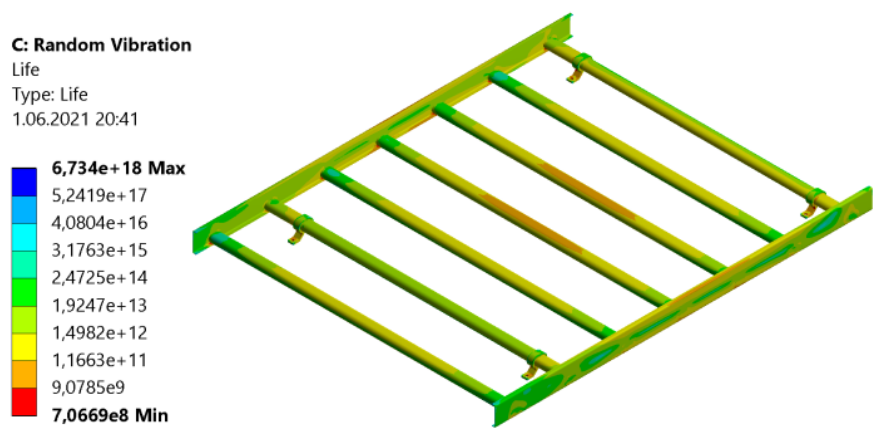

(d)

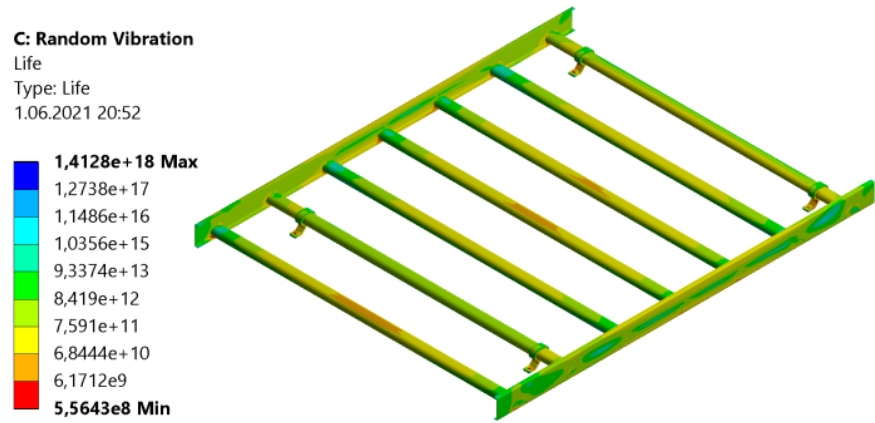

Fig. 15. Fatigue life a) Scenario $10-30 \mathrm{~km} / \mathrm{h}$ b) Scenario $130-60$ $\mathrm{km} / \mathrm{h} \mathrm{c}$ ) Scenario $160-80 \mathrm{~km} / \mathrm{h}$ d) Scenario $2105 \mathrm{~km} / \mathrm{h}$ 


\section{Conclusions and Recommendations}

Random vibration is a linear analysis. The excitation is implemented as PSD statistical input. The base excitation could be an acceleration PSD in acceleration squared units, or $G$ squared units a velocity PSD or a displacement PSD. In random vibration analysis, since the input excitation is statistical, the output responses such as displacements are stressed. The most distinctive feature of random vibration is not cyclic.

In both scenarios, cars had comparable PSD summit frequencies within the $45-70 \mathrm{~Hz}$ frequency area in the Skoda Superb and Ford Taurus car.

In this paper, random vibration analysis was applied by defining a $75 \mathrm{~kg}$ load on the car roof luggage carrier applied according to the vibration and PSD data obtained according to the vehicle's engine, wind, and road conditions. It was estimated that no fatigue damage would occur for a minimum of 103653 hours using the Steinberg's method. If this study is repeated with different vehicles' PSD data in future studies, fatigue life can be estimated more precisely.

\section{References}

Al-Yafawi, A., Patil, S., Yu, D., Park, S., Pitarresi, J., \& Goo, N. (2010). Random vibration test for electronic assemblies fatigue life estimation. 2010 12th IEEE Intersociety Conference on Thermal and Thermomechanical Phenomena in Electronic Systems, 1-7. https://doi.org/10.1109/ITHERM.2010.5501295

An, T., Qin, F., Zhou, B., Chen, P., Dai, Y., Li, H., \& Tang, T. (2019). Vibration lifetime estimation of PBGA solder joints using Steinberg model. Microelectronics Reliability, 102, 113474. https://doi.org/10.1016/j.microrel.2019.113474

Aykan, M., \& Çelik, M. (2009). Vibration fatigue analysis and multi-axial effect in testing of aerospace structures. Mechanical Systems and Signal Processing, 23(3), 897-907. https://doi.org/https://doi.org/10.1016/j.ymssp.2008.08.006

Ballesteros, E. L. (2018). Failure Prediction of Structures Subjected to Random Vibrations. The University Of Arizona.

Ben Fekih, L., Kouroussis, G., \& Verlinden, O. (2015). Verification of empirical warp-based design criteria of space electronic boards. Microelectronics Reliability, 55(12), 2786-2792. https://doi.org/10.1016/j.microrel.2015.09.031

Budynas, R. G., Nisbett, J. K., \& Tangchaichit, K. (2005). Shigley's mechanical engineering design. McGraw Hill New York.

Česnik, M., Slavič, J., Capponi, L., Palmieri, M., Cianetti, F., \& Boltežar, M. (2018). The relevance of non-stationarities and non-Gaussianities in vibration fatigue. MATEC Web of Conferences, $\quad 165, \quad 1-9$. https://doi.org/10.1051/matecconf/201816510011

Che, F. X., \& Pang, J. H. L. (2009). Vibration reliability test and finite element analysis for flip chip solder joints. Microelectronics Reliability, 49(7), 754-760. https://doi.org/https://doi.org/10.1016/j.microrel.2009.03.02 2

Chen, Y. S., Wang, C. S., \& Yang, Y. J. (2008). Combining vibration test with finite element analysis for the fatigue life estimation of PBGA components. Microelectronics Reliability, 48(4), 638-644. https://doi.org/https://doi.org/10.1016/j.microrel.2007.11.00

e-ISSN: 2148-2683
6

Chin, I., Wong, S. F., Malatkar, P., \& Canham, R. (2008). A mechanical fatigue assessment methodology to study solder joint reliability. $200833 \mathrm{rd}$ IEEE/CPMT International Electronics Manufacturing Technology Conference (IEMT), 1-9. https://doi.org/10.1109/IEMT.2008.5507797

Chipman, C., \& Avitabile, P. (2012). Expansion of transient operating data. Mechanical Systems and Signal Processing, 31 , $1-12$. https://doi.org/https://doi.org/10.1016/j.ymssp.2012.04.013

Dehbi, A., Ousten, Y., Danto, Y., \& Wondrak, W. (2005). Vibration lifetime modelling of PCB assemblies using steinberg model. Microelectronics Reliability, 45(9-11), 1658-1661. https://doi.org/10.1016/j.microrel.2005.07.074

Demirel, G. I., \& Kayran, A. (2019). Implementation of Dirlik's damage model for the vibration fatigue analysis. Procedia Structural Integrity, 21, 101-111. https://doi.org/10.1016/j.prostr.2019.12.091

enDAQ. (2021). https://endaq.com/pages/power-spectral-density

Gao, D., Yao, W., \& Wu, T. (2019). A damage model based on the critical plane to estimate fatigue life under multi-axial random loading. International Journal of Fatigue, 129, 104729.

https://doi.org/https://doi.org/10.1016/j.ijfatigue.2018.06.02 5

García, A., Sorribes-Palmer, F., \& Alonso, G. (2018). Application of Steinberg vibration fatigue model for structural verification of space instruments. AIP Conference Proceedings, 1922(January). https://doi.org/10.1063/1.5019088

Ge, J., Sun, Y., Zhou, S., Zhang, L., Zhang, Y., \& Zhang, Q. (2015). A hybrid frequency-time domain method for predicting multiaxial fatigue life of 7075-T6 aluminium alloy under random loading. Fatigue and Fracture of Engineering Materials and Structures, 38(3), 247-256. https://doi.org/10.1111/ffe.12224

Gharaibeh, M. A. (2020). A numerical study on the effect of the fixation methods on the vibration fatigue of electronic packages. Microelectronics Reliability, 115, 113967. https://doi.org/10.1016/j.microrel.2020.113967

Gharaibeh, M. A., \& Pitarresi, J. M. (2019). Random vibration fatigue life analysis of electronic packages by analytical solutions and Taguchi method. Microelectronics Reliability, 102, 113475. https://doi.org/10.1016/j.microrel.2019.113475

Halfpenny, A., \& Kihm, F. (2010). Rainflow Cycle Counting And Acoustic Fatigue Analysis Techniques For Random Loading. 10th International Conference on Recent Advances in Structural Dynamics. http:/f1000.com/work/item/2907600/resources/2155739/pdf

He, G., Chen, H., \& He, X. (2015). Fatigue behavior and influence factor analysis of the structure subject to multiaxial random loading. Journal of Vibroengineering, 17(7), 3620-3634

Jiregna, I., \& Sirata, G. (2020). A review of the vehicle suspension system. Journal of Mechanical and Energy Engineering, 4.

Kersch, K., Schmidt, A., \& Woschke, E. (2020). Multiaxial fatigue damage evaluation: A new method based on modal velocities. Journal of Sound and Vibration, 476, 115297. https://doi.org/10.1016/j.jsv.2020.115297

Kihm, F., Rizzi, S., Ferguson, N., \& Halfpenny, A. (2013). Understanding how kurtosis is transferred from input acceleration to stress response and it's influence on fatigue 
life. Rasd 2013, July, 16.

Kim, S.-W., Choi, H.-S., Jeon, B.-G., \& Hahm, D.-G. (2019). Low-cycle fatigue behaviors of the elbow in a nuclear power plant piping system using the moment and deformation angle. Engineering Failure Analysis, 96, 348-361. https://doi.org/https://doi.org/10.1016/j.engfailanal.2018.10. 021

Kong, Y. S., Abdullah, S., Haris, S. M., Omar, M. Z., \& Schramm, D. (2018). Generation of artificial road profile for automobile spring durability analysis. Jurnal Kejuruteraan, 30(2), 123-128.

Leitner, B., \& Figuli, L. (2018). Fatigue life prediction of mechanical structures under stochastic loading. MATEC Web of Conferences, 157, 1-11. https://doi.org/10.1051/matecconf/201815702024

Li, L., Gu, X., Sun, S., Wang, W., Wan, Z., \& Qian, P. (2018). Effects of welding residual stresses on the vibration fatigue life of a ship's shock absorption support. Ocean Engineering, 170, 237-245. https://doi.org/10.1016/j.oceaneng.2018.10.011

Li, R. S. (1999). A Methodology for Fatigue Prediction of Electronic Components Under Random Vibration Load . Journal of Electronic Packaging, 123(4), 394-400. https://doi.org/10.1115/1.1372318

Li, Y., Mulani, S. B., Fei, Q., Wu, S., \& Zhang, P. (2017). Vibroacoustic analysis under stationary and non-stationary random excitations with KLE/FEM/BEM. Aerospace Science and Technology, 66, 203-215. https://doi.org/https://doi.org/10.1016/j.ast.2017.03.011

Luo, P., Yao, W., \& Li, P. (2019). A notch critical plane approach of multiaxial fatigue life prediction for metallic notched specimens. Fatigue and Fracture of Engineering Materials and Structures, 42(4), 854-870. https://doi.org/10.1111/ffe. 12956

Luo, Z., Chen, H., \& He, X. (2020). Influences of correlations between biaxial random vibrations on the fatigue lives of notched metallic specimens. International Journal of Fatigue, 139,

105730. https://doi.org/10.1016/j.ijfatigue.2020.105730

Luo, Z., Chen, H., He, X., \& Zheng, R. (2019). Two time domain models for fatigue life prediction under multiaxial random vibrations. Proceedings of the Institution of Mechanical Engineers, Part C: Journal of Mechanical Engineering Science, 233(13), 4707-4718. https://doi.org/10.1177/0954406219827038

Mršnik, M., Slavič, J., \& Boltežar, M. (2013). Frequencydomain methods for a vibration-fatigue-life estimation Application to real data. International Journal of Fatigue, 47 , $8-17$. https://doi.org/https://doi.org/10.1016/j.ijfatigue.2012.07.00 5

Mršnik, M., Slavič, J., \& Boltežar, M. (2016). Multiaxial vibration fatigue-A theoretical and experimental comparison. Mechanical Systems and Signal Processing, 76-77, 409-423. https://doi.org/https://doi.org/10.1016/j.ymssp.2016.02.012

Park, T. Y., \& Oh, H. U. (2021). New PCB strain-based structural design methodology for reliable and rapid evaluation of spaceborne electronics under random vibration. International Journal of Fatigue, 146, 106147. https://doi.org/10.1016/j.ijfatigue.2021.106147

Perkins, A., \& Sitaraman, S. K. (2004). Vibration-induced solder joint failure of a Ceramic Column Grid Array (CCGA) package. 2004 Proceedings. 54th Electronic Components and Technology Conference (IEEE Cat. No.04CH37546), 2, 1271-1278

Vol.2.

https://doi.org/10.1109/ECTC.2004.1320277

Pitarresi, J. M. (1990). Modeling of printed circuit cards subject to vibration. IEEE International Symposium on Circuits and Systems, 2104-2107 vol.3. https://doi.org/10.1109/ISCAS.1990.112213

Pitarresi, J. M., Caletka, D. V, Caldwell, R., \& Smith, D. E. (1991). The "Smeared" Property Technique for the FE Vibration Analysis of Printed Circuit Cards. Journal of Electronic Packaging, 113(3), 250-257. https://doi.org/10.1115/1.2905403

Poshtan, E. A., Xingyuan, C., \& Roessle, A. (2018). Resonance frequency dependency of Thermal Interface Materials (TIM) under vibration. 2018 19th International Conference on Thermal, Mechanical and Multi-Physics Simulation and Experiments in Microelectronics and Microsystems (EuroSimE), https://doi.org/10.1109/EuroSimE.2018.8369948

Putra, T. E., Abdullah, S., \& Schramm, D. (2020). Effect of cycle amplitude removal of fatigue strain loadings associated to signal energy characteristics. Engineering Failure Analysis, 116 ,

104723. https://doi.org/10.1016/j.engfailanal.2020.104723

Putra, T. E., Abdullah, S., Schramm, D., Nuawi, M. Z., \& Bruckmann, T. (2015). Generating strain signals under consideration of road surface profiles. Mechanical Systems and Signal Processing, 60-61, 485-497. https://doi.org/https://doi.org/10.1016/j.ymssp.2015.01.031

Rahim, A. A. A., Abdullah, S., Singh, S. S. K., \& Nuawi, M. Z. (2021). Fatigue strain signal reconstruction technique based on selected wavelet decomposition levels of an automobile coil spring. Engineering Failure Analysis, 125, 105434. https://doi.org/10.1016/j.engfailanal.2021.105434

Rouillard, V. (2007). On the Non-Gaussian Nature of Random Vehicle Vibrations. Lecture Notes in Engineering and Computer Science, 2166(1), 1219-1224.

Schriefer, T., \& Hofmann, M. (2019). A hybrid frequency-timedomain approach to determine the vibration fatigue life of electronic devices. Microelectronics Reliability, 98, 86-94. https://doi.org/10.1016/j.microrel.2019.04.001

Steinberg, D. S. (1976). Avoiding vibration in odd-shaped printed circuit boards. Machine Design, 48(12), 116-119.

Steinberg, D. S. (1988). Tools available for implementing AVIP. Ninth Annual IEEE/AESS Dayton Chapter Symposium 'Avionics Integrity Program, 23-31. https://doi.org/10.1109/DAYTON.1988.76014

Tao, S., Chen, B., \& Fan, X.-J. (n.d.). Structural Fatigue Life Prediction Based on ANSYS Random Vibration Analysis. Proceedings of the 4th 2016 International Conference on Material Science and Engineering (ICMSE 2016), 235-238. https://doi.org/https://doi.org/10.2991/icmse-16.2016.39

Trapp, A., Makua, M. J., \& Wolfsteiner, P. (2019). Fatigue assessment of amplitude-modulated non-stationary random vibration loading. Procedia Structural Integrity, 17, 379386. https://doi.org/10.1016/j.prostr.2019.08.050

Trapp, A., \& Wolfsteiner, P. (2019). Characterizing nonGaussian vibration loading using the trispectrum. Journal of Physics: Conference Series, 1264(1). https://doi.org/10.1088/1742-6596/1264/1/012040

Trapp, A., \& Wolfsteiner, P. (2021). Frequency-domain characterization of varying random vibration loading by a 
non-stationarity matrix. International Journal of Fatigue, 146, 106115. https://doi.org/10.1016/j.ijfatigue.2020.106115

Troncossi, M., \& Pesaresi, E. (2019). Analysis of synthesized non-Gaussian excitations for vibration-based fatigue life testing. Journal of Physics: Conference Series, 1264(1). https://doi.org/10.1088/1742-6596/1264/1/012039

Wen, C., Xie, B., Li, Z., Yin, Y., Zhao, X., \& Song, Z. (2020). Power density based fatigue load spectrum editing for accelerated durability testing for tractor front axles. Biosystems Engineering, 200, 73-88. https://doi.org/10.1016/j.biosystemseng.2020.09.008

Wirsching, P. H., Paez, T. L., \& Ortiz, K. (2006). Random vibrations: theory and practice. Courier Corporation.

Wong, T. E., Palmieri, F. W., Reed, B. A., Fenger, H. S., Cohen, H. M., \& Teshiba, K. T. (2000). Durability/reliability of BGA solder joints under vibration environment. 2000 Proceedings. 50th Electronic Components and Technology Conference (Cat. No.00CH37070), 1083-1088. https://doi.org/10.1109/ECTC.2000.853304

Xia, J., Yang, L., Liu, Q., Peng, Q., Cheng, L. X., \& Li, G. Y. (2019). Comparison of fatigue life prediction methods for solder joints under random vibration loading. Microelectronics Reliability, 95, 58-64. https://doi.org/10.1016/j.microrel.2019.02.008

Yang, Q. J., Pang, H. L. J., Wang, Z. P., Lim, G. H., Yap, F. F., \& Lin, R. M. (2000). Vibration reliability characterization of PBGA assemblies. Microelectronics Reliability, 40(7), 1097-1107. https://doi.org/https://doi.org/10.1016/S00262714(00)00036-6

Yu, D., Al-Yafawi, A., Nguyen, T. T., Park, S., \& Chung, S. (2011). High-cycle fatigue life prediction for Pb-free BGA under random vibration loading. Microelectronics Reliability, 51(3), 649-656. https://doi.org/10.1016/j.microrel.2010.10.003

Yuan, Z., Ma, H., Lu, Y., Zhu, S., \& Hong, T. (2019). The application of load identification model on the weld line fatigue life assessment for a wheel loader boom. Engineering Failure Analysis, 104, 898-910. https://doi.org/https://doi.org/10.1016/j.engfailanal.2019.06. 077

Zakaria, K. A., Idris, M. I. F., Dharmalingam, S., SuhailaSalleh, Sanusi, N., \& Daud, M. A. M. (2018). Fatigue strain signal characteristic and damage of automobile suspension system. ARPN Journal of Engineering and Applied Sciences, 13(1), 221-225. https://www.scopus.com/inward/record.uri?eid=2s2.0-

85040537934\&partnerID=40\&md5=44cba71ac1b0bf73743 098b745841e82

Zhang, J., Fu, X., Lin, J., Liu, Z., Liu, N., \& Wu, B. (2018). Study on Damage Accumulation and Life Prediction with Loads below Fatigue Limit Based on a Modified Nonlinear Model. Materials, 11(11). https://doi.org/10.3390/ma11112298

Zhou, H., Wang, Z.-W., \& Zhi-Wei Wang, C. (2018). Measurement and analysis of vibration levels for express logistics transportation in South China. https://doi.org/10.1002/pts.2404

Zhou, Y, Al-Bassyiouni, M., \& Dasgupta, A. (2010). Harmonic and Random Vibration Durability of SAC305 and Sn37Pb Solder Alloys. IEEE Transactions on Components and Packaging Technologies, 33(2), 319-328. https://doi.org/10.1109/TCAPT.2009.2036834

Zhou, Yadong, \& Tao, J. (2019). Theoretical and numerical investigation of stress mode shapes in multi-axial random fatigue. Mechanical Systems and Signal Processing, 127, 499-512.

https://doi.org/https://doi.org/10.1016/j.ymssp.2019.03.015 